\title{
PERFORMANCE OF EXISTING REINFORCED CONCRETE ARCH BRIDGES UNDER CURRENT NON SEISMIC LOADS
}

\author{
Giovanni Crisci ${ }^{1}$, Francesca Ceroni ${ }^{1}$, Gian Piero Lignola ${ }^{2}$ and Andrea Prota $^{2}$ \\ ${ }^{1}$ Engineering Department, University of Naples "Parthenope", \\ Centro Direzionale is. C4, 80143, Napoli, Italy \\ \{giovanni.crisci, francesca.ceroni\}@uniparthenope.it \\ ${ }^{2}$ Department of Structures for Engineering and Architecture, University of Napoli "Federico II", \\ Via Claudio, 21, 80125, Napoli, Italy, \\ \{glignola, aprota\}@unina.it
}

\begin{abstract}
The present analytical work deals with the assessment of the performances of Reinforced Concrete (RC) Deck Arch Bridges under the non-seismic loading conditions required by the current mandatory Italian codes. In particular, the attention is focused on a specific RC deck arch bridge typology, better known as the "Maillart Type Arch Bridge", which is characterized by a very stiff deck beam and a slender and wide vault. As well as other existing $R C$ structures which were designed under only gravity loads and without specific structural details, such as lower limits for longitudinal and transverse reinforcement bars, these bridges could be damaged by loading conditions not considered at the time of design. For the evaluation of the main critical issues related to the current performance of such bridges under the current non-seismic loading conditions, it has been defined a large inventory of simulated arch bridges in accordance to the design procedures usually adopted in 1950s which considered only gravitational loads, i.e. self-weight and moving loads. Each bridge of the inventory is modelled and studied by means of a Linear Gravitational analysis implemented in the structural software SAP2000, with support of an Application Programming Interface (API), such as Matlab.

Due to the differences between the current loads and those considered at the design time and to the approximations of the design strategies of the time, a performance-based analysis of the existing bridges under non-seismic loads is important for the stakeholders as much as for the decision - makers in order to plan risk mitigation programs and prioritize eventual retrofit interventions for risk reduction.
\end{abstract}

Keywords: RC Arch Bridges, Maillart Bridges, Gravitational loads, Vulnerability Analysis. 


\section{INTRODUCTION}

In recent years, considerations and rehabilitations of existing bridges have been an ongoing problem for the bridge administrations and for their owners in almost all countries. The performance level of an existing bridge is often inadequate: indeed, the always increasing number of vehicles and of traffic and the heavier weight loads, have made the structural safety of existing infrastructure system progressively insufficient even under vertical loads only.

In Italy, the Reinforced Concrete (RC) arch bridges are today still one of the most important part of the transportation system. Such bridges, designed and built around 50s, and in most cases under-designed for the nowadays serviceability conditions, require particularly attention due to their specific peculiarities that make exceptionally complex the assessment of their behavior under both static and dynamic actions. In addition to the previous "vulnerabilities", most of these structures were designed only for gravitational loads: indeed, the seismic hazard has only recently been recognized by national structural codes ([1], [2]) and this means that their current vulnerability may be much more important.

In this study, the attention is focused on a specific arch bridge typology: the "MaillartType Arch Bridges" or "Deck Stiffened Arch Bridges" ([3], [4], [5]), which are characterized by a very stiff deck beam and a slender and wide vault (with a low moment of inertia), connected the one to the other by means of slender piers, often wall-like and lightened by central windows (Figure 1). The name of this bridge typology comes from the Swiss civil engineer Robert Maillart, who first introduced a very revolutionary concept: he reversed the classic arch-to-deck stiffness ratio, realizing in this way a significant reduction of the bending moment and of the shear forces in the arch in favor of a mainly compression stress status in the arch. This led to the fact that, being the structure hyperstatic, the stiffest element also bears the highest stresses and, thus, the deck beam becomes the key element of the whole bridge, since it has to bear the most bending moments and shear forces ([6], [7]).

Nowadays, as mentioned previously, some of RC Deck Stiffened Arch Bridges built in the last century need a structural strengthening due to several environmental factors such as corrosion and degradation of materials and/or anthropological factors such as the always increasing traffic loads under serviceability conditions and/or poor maintenance [8].

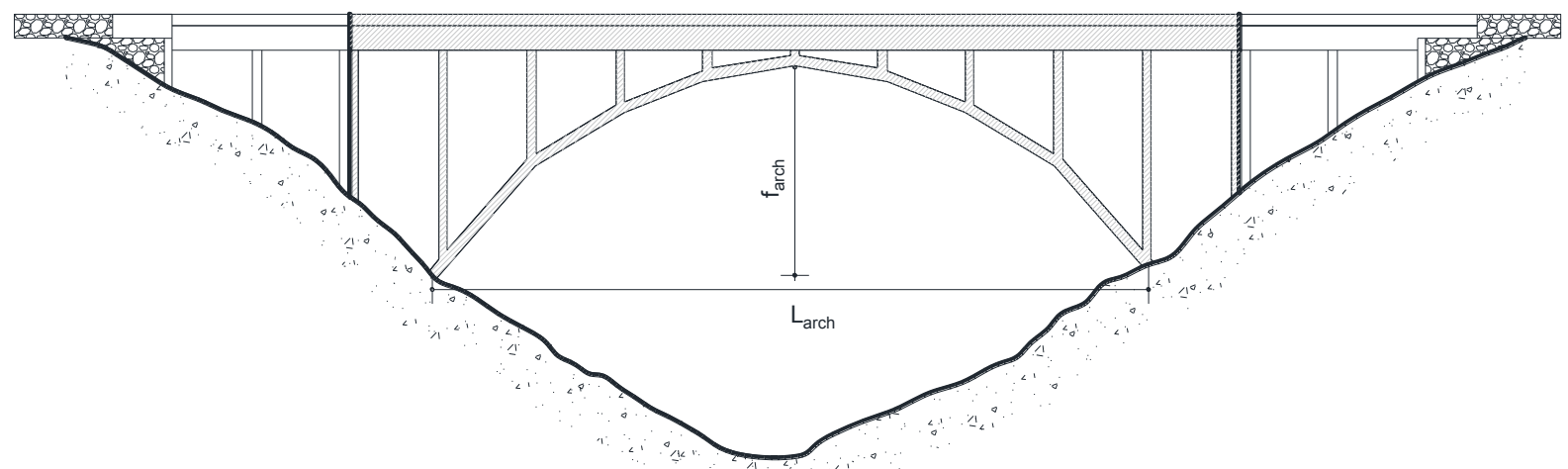

Figure 1: General view of a RC Deck Stiffened Arch Bridge.

It is worth to note that a fundamental problem in Italy is represented by the absence of a detailed database of existing infrastructures; indeed, the lack of exact information makes the role of managing entities even more difficult. An example of the particularity of the Italian 
scenario is that, in February 2019, there were about 1000 bridges whose ownership was not even known [9].

Therefore, information about damage and/or structural deficiencies of bridges is also quite rare and, additionally, details about dimensions, type and amount of materials of real structures are not available for a large number of these bridges.

The present study focusses attention on the assessment of the safety conditions of RC Deck Stiffened Arch Bridges under the current static loading conditions defined by the Italian codes ([10], [11]). Despite several bridges of this typology have been recognized in Italy, due to the lack of detailed information about them, the structural analyses herein presented have been performed with reference to a large building inventory of simulated "Maillart - Type" Arch Bridges, characterized by geometry and material properties varying in the ranges typical of the real structures. Firstly, a simulated design procedure according to the current codes at the age of construction has been used for creating the geometrical models and define the internal steel reinforcements. Then, structural analysis and safety verifications have been carried out for the samples of the collected inventory under the static loads provided by the current Italian codes $([10],[11])$.

\section{CREATION OF THE BRIDGES INVENTORY}

\subsection{Characteristics of existing "Maillart - Type" Arch Bridges in Italy}

Although the typology of girder bridges is certainly the most widespread in Italy, examples of arch bridges are also frequent. In Crisci et al., 2021 [12], after careful investigations based on examination of old projects, books and online resources, several existing $\mathrm{RC}$ arch bridges (about 90) were collected and recognized on the Italian territory. Unfortunately for most of them, it was only possible to retrieve general information on geometry, such as span length Larch and the rise of arch farch. This study allowed to identify the variability of the main geometric parameters of such structures; indeed, most of the bridges are characterized by an arch span Larch ranging between 50 and $90 \mathrm{~m}$, while a low percentage is found for the case 90$110 \mathrm{~m}$ (Figure 2a). It is worth noting that these distributions are representative of the only collected available data and, thus, they might be not fully representative of the real situation in Italy or worldwide.

Similar considerations can be summarized for the arch rise farch: a good percentage of bridges, approximately 50\%, are characterized by an arch rise ranging between $10-20 \mathrm{~m}$, whereas a lower percentage is concentrated around the values of $20-30 \mathrm{~m}$ and $30-40 \mathrm{~m}$ (Figure $2 b$ ). In Figure $2 \mathrm{c}$, the frequency distribution of the ratio farch/L is also plotted.

In addition to the arch, the structural elements of each bridge consist of a regular grid of main and secondary $\mathrm{RC}$ beams with rectangular cross sections, connected the one to the other by means of a slab. Finally, slender piers connect the vault to the deck beam. Detailed information about the dimensions of the various structural elements or the reinforcement ratios are more difficult to determine or collect, and they would require ad hoc investigations and inspections. For such reason, in Crisci et al. 2021 [12], thanks to historical documents and old designs, the typical variability of the secondary geometric characteristics has been presented, such as the dimensions of piers, beams, reinforcement ratios for the vault, piers, etc...

Thus, for the generation of the inventory, the following ranges were fixed for the main geometrical parameters:

- $\quad 50$ - $120 \mathrm{~m}$ for the arch span, $\mathbf{L}$;

- $\quad 10-40 \mathrm{~m}$ for the arch rise, $\mathbf{f}_{\text {arch; }}$;

- $\quad 0.2$ - 0.3 for the ratio, $\mathbf{f}_{\text {arch }} / \mathbf{L}$; 
- $\quad 0.30-0.45 \mathrm{~m}$ for the base of piers, $\mathbf{B}_{\mathbf{p}}$;

- $\quad 0.30-0.45 \mathrm{~m}$ for the base of the main beams, $\mathbf{B}_{\mathbf{b}, \mathbf{I}}$;

- $1.0-1.6 \mathrm{~m}$ for the height of the main beams, $\mathbf{H}_{\mathbf{b}, \mathbf{I}}$;

Note that for the parameters plotted in Figure 2, the ranges have been defined by considering the minimum and maximum values relative to the cases with greater frequency.

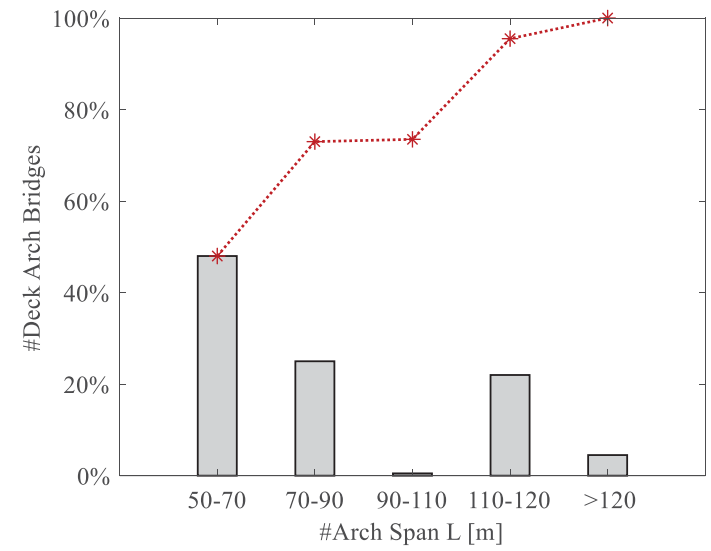

(a)

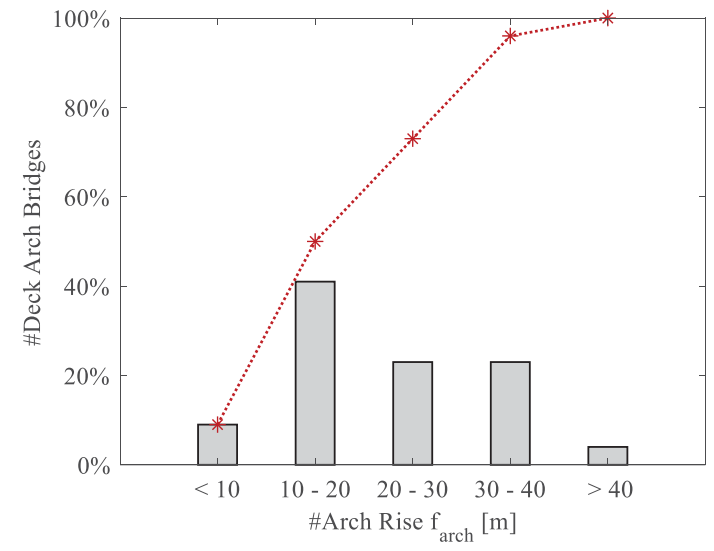

(b)

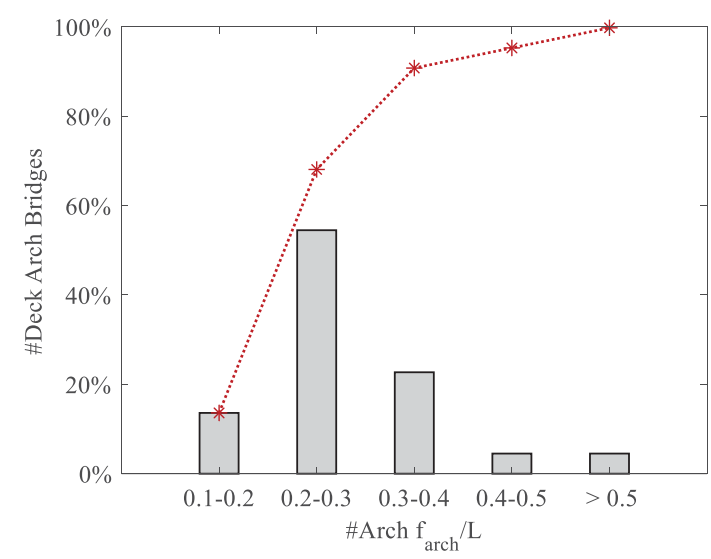

(c)

Figure 2: Distribution and cumulative percentage of bridges as: (a) function of Arch Span, L; (b) function of Arch Rise, $\mathrm{f}_{\text {arch }}$; (c) function of ratio between $\mathrm{f}_{\text {arch }} / \mathrm{L}$.

About the mechanical characteristics of the materials, historical and documented sources evidenced that it was customary to use concrete with a cubic characteristic compressive strength $R_{c k}$ of at least $36 \mathrm{MPa}$, whereas for the steel reinforcement, usually the one known as TOR60 was adopted with an average yielding stress of about $600 \mathrm{MPa}$.

A proper Bridge Inventory of more than 1500 structures has been, thus, defined by means of the Monte Carlo simulation procedure ([13]). The generation of a proper dataset is, indeed, very useful in order to study the average behaviour of a homogeneous class of structures at large scale with regards to a certain demand, that for the present study will be represented by the static loads provided by the current Italian codes.

The bridge inventory was, thus, built by changing some significant parameters such as geometrical data, mechanical and reinforcement percentages in the fixed ranges discussed previously. As regard the reinforcement percentages, they were established in accordance with the minimum values indicated by the mandatory codes of the time ([14]) and with reference to a few designs of real bridges. In particular, for the vault and the piers, the minimum 
reinforcement percentage was, on average, equal to $0.8 \%$ of the area of the concrete cross section. For the elements subjected to bending moment, on average, the reinforcement percentage varied between $0.1 \%$ and $2 \%$. Moreover, it was customary to use a transverse reinforcement (e.g. stirrups) with a very scattered distance, i.e. variable between 150 and 250 $\mathrm{mm}$.

In particular, with regard to the dimensions of the piers, it is worth to note that only the lower dimension of the vertical piers has been defined, because it is linked to the base of the main beams for geometric reasons. As regard the larger dimension, e.g. the one parallel to the longitudinal direction of the bridge, it has been obtained as a function of the slenderness, $\lambda$, of the structural element. Indeed, in order to reduce the effects of the second order, it was usual at the time to set the slenderness of the piers to a limit value of 50 .

Generally, the extraction of the parameters should take place with reference to a probability distribution, but, due to the limited number of known reference structures and, thus, to the limited knowledge of the actual distribution of each parameter in the real structures, the parameters have been drawn assuming a uniform probability distribution for each of them.

Moreover, in order to exclude the combinations of geometric and mechanical parameters which could lead to bridges structurally not verified nor realistic, each generated arch bridge was subsequently verified with reference to the vertical loads of the time, i.e. according to the mandatory codes of the time. These verifications, explained in the following, have been carried out according to the structural schemes and analysis procedures of the time that were simpler in comparison with those adopted nowadays thanks to the aid of numerical software.

\subsection{Verifications of "Maillart - Type" Arch Bridges according to the codes of the time}

Once the bridge inventory has been defined, the geometric and mechanical characteristics of each structure are known, such as arch span and rise, dimensions of piers, principal and secondary beams, steel reinforcement ratio, and so on. For each bridge, a simulated design has been carried out according to the mandatory codes at the time of design in order to verify the correct size and the reinforcement layers assigned to the various structural elements (Crisci et al. 2021 [12]) and to exclude non-realistic combinations of geometric and mechanical parameters. In this section the steps followed for carrying out these verifications are described.

The starting point for building the geometry of a deck arch bridge is the definition of its arch; a common practice of the time consisted into design the axis of the arch in order to be funicular of the gravitational loads corresponding to the self-weight only of the entire structure. This means that the arch is subjected to axial compression force only, without any bending moment and shear force. The calculation of the stresses acting on each arch has been done considering a simplified model in agreement with the assumptions commonly done by the designers of the time, i.e., an equivalent two-dimensional structure, characterized by a continuous deck beam supported by the piers, a hinged arch at both springings, and axially rigid piers connected to both the arch and the deck beam by means of hinges.

The load combinations were fixed with reference to the mandatory codes in force at the time, in particular the Royal Decree of 1939 [14] and the Circular n. 6018 concerning the loads on bridges of 1945 [15]. In particular, two different types of loading schemes were adopted:

1. Two or more undefined trains of trucks weighing 12 tons (about $120 \mathrm{kN}$ ) side by side;

2. Two compressor rollers weighing 18 tons each (about $180 \mathrm{kN}$ ) side by side.

In addition, a compact crowd was expected on the sidewalks next to the driveway.

The assessment of maximum stresses was carried out by placing the moving loads, given by the loading condition 1 [15], in the most unfavourable position on the deck, which was 
found by means of the Influence Lines. Figure 3 shows some of the influence lines adopted for the verification of the structural elements of bridges, i.e. the influence lines of bending moments for moving vertical loads in one cross section of the deck (magenta line) and of the horizontal trust in the arch (yellow line).

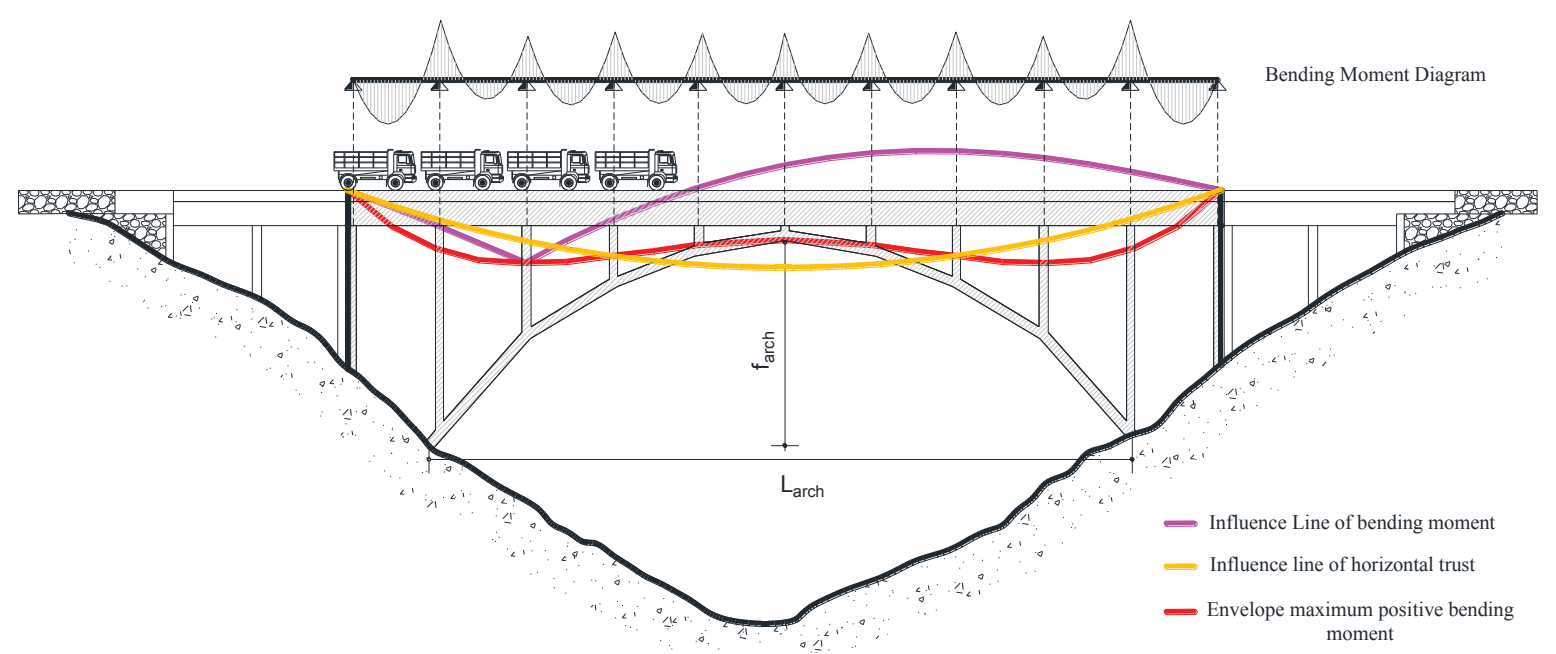

Figure 3: Examples of influence line of bending moment on the deck, horizontal thrust and position of moving loads able to maximize the bending stress.

It is worth to note that the position of the moving loads giving the maximum bending moment on the deck does not yield the maximum horizontal thrust in the arch as well. Indeed, in order to maximize the horizontal thrust, $\mathrm{H}$, and so the compression force, $\mathrm{N}$, in the arch as well, the moving loads must be applied on the whole entire deck. Under this latter load condition, the piers were verified as well.

The envelope of all the positive and negative peaks of each magenta line represents the diagram of the maximum and minimum bending moments from which it is possible to identify the cross section and, therefore, the position of the moving loads able to maximize the bending moment on the deck beam. For simplicity, in Figure 3, the only envelope of the maximum positive bending moments is plotted (red line); the envelope of the minimum negative bending moments is, indeed, mirrored to this one.

Conversely, the secondary beams have been verified with reference to their tributary area to define the entity of the gravitational loads (uniformly distributed loads) and with reference to the worst condition for the moving loads, i.e. when the axis of the vehicle is just on the secondary beam. Moreover, the constraint conditions at the ends of the secondary beams have been assumed as ranging between a simple supported beam and a fully fixed beam, in order to maximize the positive and negative bending moments along the element.

According to the Royal Decree of 1939 [14], the design of steel reinforcement in the beams was made with respect to "Allowable Stress Method (ASM)" [16], where the working stress is defined as the $5 \%$ percentile strength divided by a safety factor, equal to 3 for concrete and 2 for steel. On the basis of the stress distributions in each element under the previously cited load combinations, each generated arch bridge has been verified with reference to both flexural, normal and shear stresses. If some verifications are not satisfied, the bridge has been excluded from the database under the assumption that the casual combinations of the parameters have led to hypothesize a structure not in agreement with design rules and loads of the time and, thus, not representative of an existing bridge. Clearly, for the not verified 
samples, a different choice of some parameters, as, for example, the reinforcement percentage or the dimensions of some structural elements, might lead to a representative structure, but lacking more detailed information on these parameters, this option was not pursued. Therefore, in place of the excluded cases, other bridges were extracted, as long as the sample size was satisfactory and the geometrical parameters assumed for the generation of the sample were equally distributed.

\subsection{Creation of 3D Finite Element Models}

Once each geometric model has been designed and verified according to a simplified methodology and in agreement with the loads and rules of the time, a 3D Finite Element Model (FEM) is implemented using the software SAP2000 [17]. Two node - frame elements, i.e. beam elements with three translational and three rotational degrees-of-freedom (DOF) at each node have been used to model the beams, the piers and the arch. Moreover, the eccentricities of the piers with regard to the axis of the vault have been taken into account by means of rigid offsets and massless links. In Crisci et al., 2020 [6] it was, indeed, verified that no significant differences in the stresses in all structural elements occur if the vault is modelled by two-dimensional elements instead of frame elements with offsets. This latter solution was preferred in order to reduce the computational effort also in view of the analyses under seismic actions.

About the constraint conditions of the piers, it is worth to remember that usually at the time of design the piers were modelled as pendulums, i.e. simply hinged at both ends, under the gravitational loads and, thus, they resulted subjected to axial loads only. The choice of modelling the piers as pendulums was related to the reduction of the hyperstatic unknowns and, thus, of the complexity of the solution of the structural scheme of the bridge, but, at the same time, led also to a reduction of the differences in stiffness of the deck beam and the vault. However, some design documents of the time have evidenced that in many cases the piers were realized as fixed at the end, as testified by constructive details, and were, thus, subjected to some shear and bending actions as well. For this reason, in the SAP2000 model the piers have been considered fixed constrained at their both ends and not connected by simple hinges to the arch and the deck. It is worth noting that the entity of the shear and bending actions transferred to the piers under gravitational loads was limited due to the high difference of stiffness between the deck and the arch and, thus, between deck and piers [6].

The deck slab, on the contrary, has been considered only in terms of loads acting on the main beams, while a "diaphragm" constraint has been used to simulate its behaviour on the bridge deck. Fixed supports at ends of the arch have been assumed; this assumption is well accepted when bridge foundation is over bedrock sites, i.e. ground type A [10], as it is the case for the majority of this type of bridges. With reference to the deck constraints, the generic bridge was assumed to be constrained along the longitudinal direction in order to simulate the presence of abutments or of other roads which could limit its displacement, whereas it was considered free along the out - of - plane direction.

Each structural element is modelled as elastic and, in order to take into account the development of cracking phenomena in the concrete, the effective moment of inertia of the beams has been reduced by $50 \%$, while by only $25 \%$ for the vertical piers and the arch according to the prevalent compression forces in the elements ([10], [18]). No reduction of the transverse area, torsion and shear area has been considered [19]. This procedure was automatized adopting specific software such as MATLAB [20], where by means of Open Application Programming Interface (OAPI), it is possible to integrate with structural software, such as SAP2000 [17], to run analysis on a multitude of several models. 


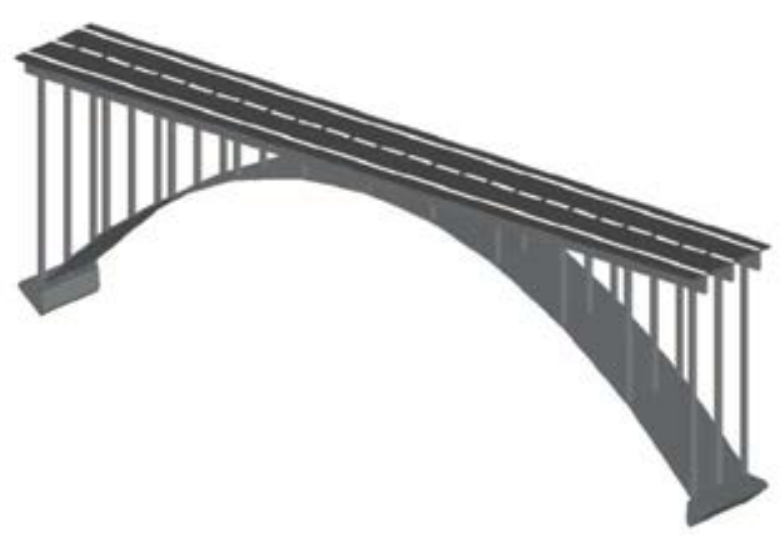

(a)

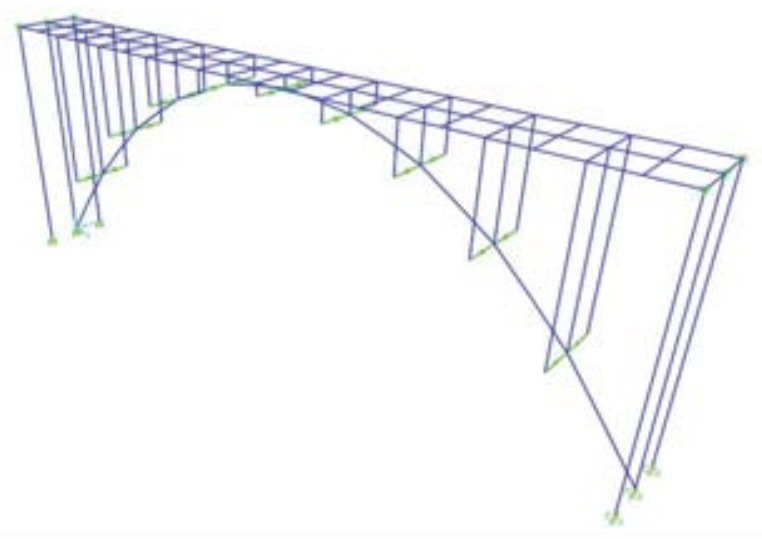

(b)

Figure 4: (a) Geometric model of RC Deck Stiffened Arch Bridge; (b)Three Dimensional (3D) FEM.

\section{ASSESSEMENT OF TRAFFIC LOADS ACCORDING TO ITALIAN CODES}

As reported in section 1 , the demand in terms of traffic loading is very different nowadays if compared to the past. This study is, indeed, aimed to highlight which are the main structural deficiencies of existing bridges, especially for arch bridges designed and built with regards to the rules of $40 \mathrm{~s}$, under the non-seismic loads prescribed by the current codes, i.e. the new guidelines for existing bridges [11] and the Italian code for structures [10]. This is a fundamental aspect that has to be investigated prior to proceed with the verifications under seismic actions. It is worth to note that, for structural purposes, according to new guidelines [11], each generated arch bridge was assumed to be classified as CC3, i.e. Consequences Class 3, that means "high consequence for loss of human life, or economic, social or environmental consequences very great, such as bridges, public buildings, where consequences of failure are high". The structural verifications were carried out considering the loads according to the new guidelines for bridges [11], that entail to assume the same partial safety coefficients prescribed by [10].

The structural analyses were performed considering, in addition to the structural and non structural weights, e.g. road pavement, the moving loads schemes in accordance with [10]. The latter, shown in Figure 5, also include the dynamic effects due to the passage of vehicles on the structures, and they are the reference schemes that have to be used for the global structural verifications of the bridge structures.

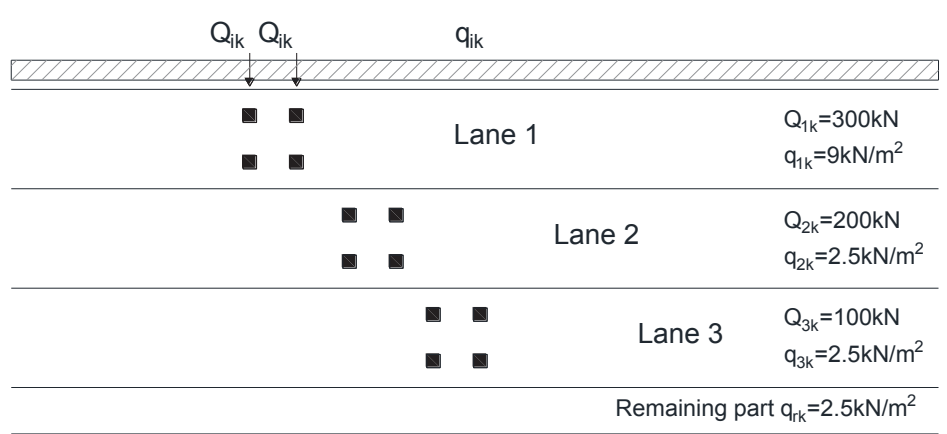

Figure 5: Moving loads according to Italian Building Code 2018 [10].

Moreover, it has been considered the braking actions of the vehicles, which are applied as uniformly distributed loads on the axis of the lane. In addition to the moving loads, the loads 
related to temperature, wind and snow have been considered as well, assuming for simplicity a climatic zone III and an altitude of less than 200m [10].

In order to define the characteristic values (i.e. the $5 \%$ percentile values) of the traffic loads, the loading schemes have been combined by considering two groups of actions, respectively the group 1 and the group 2a, as reported in [10]. The first group considers the characteristic values of the moving loads without taking into account the braking actions. The group $2 \mathrm{a}$, on the other hand, considers the frequent values of the moving loads and takes into account the characteristic values of the braking actions. Finally, the various actions have been combined with the fundamental combination at the Ultimate Limit State, obtaining a total of 9 individual load combinations, as Table 1 shows.

Tab 1: Load combinations at the Ultimate Limit State according to ([10], [11])

\begin{tabular}{|c|c|c|c|c|c|c|c|c|}
\hline \multirow{2}{*}{ ID } & \multirow{2}{*}{$\mathbf{G}_{\mathbf{k} 1}$} & \multirow{2}{*}{$\mathbf{G}_{\mathrm{k} 2}$} & \multicolumn{3}{|c|}{$\mathbf{Q}_{\mathrm{k}}$} & \multirow{2}{*}{ Wind } & \multirow{2}{*}{ Snow } & \multirow{2}{*}{ Temperature } \\
\hline & & & $\mathbf{Q}_{\mathrm{ik}}$ & $q_{i k}$ & Braking & & & \\
\hline 1 & 1.35 & 1.5 & 1.35 & 1.35 & - & 0.9 & - & 0.72 \\
\hline 2 & 1.35 & 1.5 & 1.01 & 0.54 & 1.35 & 0.9 & - & 0.72 \\
\hline 3 & 1.35 & 1.5 & 1.01 & 0.54 & - & 1.5 & - & 0.72 \\
\hline 4 & 1.35 & 1.5 & 1.01 & 0.54 & 0.54 & 1.5 & - & 0.72 \\
\hline 5 & 1.35 & 1.5 & 1.01 & 0.54 & - & 0.9 & 1.5 & 0.72 \\
\hline 6 & 1.35 & 1.5 & 1.01 & 0.54 & 0.54 & 0.9 & 1.5 & 0.72 \\
\hline 7 & 1.35 & 1.5 & 1.01 & 0.54 & - & 0.9 & - & 1.20 \\
\hline 8 & 1.35 & 1.5 & 1.01 & 0.54 & 0.54 & 0.9 & - & 1.20 \\
\hline 9 & 1.35 & 1.5 & - & - & - & 0.9 & - & 0.72 \\
\hline
\end{tabular}

The structural verifications have been carried out with reference to both the ductile (flexural verifications) and brittle mechanisms (shear verifications) in terms of capacity at the Ultimate Limit State (ULS), in accordance to [10]. For the flexural capacity, in order to take into account the presence of biaxial bending moments, the following Bresler's equation has been adopted:

$$
\left(\frac{M_{E d, x}}{M_{R d, x}}\right)^{\alpha}+\left(\frac{M_{E d, y}}{M_{R d, y}}\right)^{\beta} \leq 1
$$

being $\mathrm{MEd,x}_{\mathrm{x}}$ and $\mathrm{M}_{\mathrm{Ed}, \mathrm{y}}$ the bending moments around the two principal axes, $\mathrm{x}$ and $\mathrm{y}$, of the cross sections and come from the 9 loads combinations, $M_{R d, x}$ and $M_{R d, y}$ the flexural capacity of the section evaluated with respect to the $\mathrm{x}$ and $\mathrm{y}$ axis respectively, $\alpha$ and $\beta$ two shape coefficients, which for rectangular cross section have been assumed equal to 1.5.

As regard the shear capacity, two different approaches have been considered for the arch and for the beams. Due to the presence of longitudinal steel reinforcement only, for the arch the shear strength for members without shear reinforcement given by ([10], [18]) has been used, while for the piers and the beams, which are supposed to have steel stirrups, the shear capacity has been evaluated according to the strength model proposed by [21] in order to take into account the significant benefit of the compression force in the piers on their ultimate shear capacity.

\section{DISCUSSION OF RESULTS}

Each simulated bridge has been studied with reference to the several combinations of loads discussed above; in particular, the results are represented in terms of DCR, i.e. Demand over 
Capacity Ratio, where the Demand and the Capacity are represented by bending moment, shear or axial force. It is worth to point out that, as more than 1500 Maillart-Type Arch Bridges have been generated and verified, the results will be represented in the following in terms of maximum DCR ratio for each bridge with reference to the main stress acting in the various structural elements, e.g. arch, piers and beams, and with reference to the considered load combinations. This means that for each structural element the worst safety condition is represented.

The Figure 6 shows the trend of the maximum DCR for the arch, in the case of flexural and shear verifications, as a function of the span (6a and $6 \mathrm{~b})$ and the rise of the arch (6c and $6 \mathrm{~d})$; it is clear that structural problems do not arise in any case for the arch. In particular, the maximum DCR, for flexural verifications, is about 0.8 , whereas it is about 0.5 for shear verifications. In order to better read the trend of DCR, a linear regression line has been represented too: it is observed that the average trend, as function of both the span and the rise, is increasing in the case of flexural verifications (minimum value of about 0.2 and maximum value of about 0.6), while it is rather constant for shear verifications (approximately 0.4).

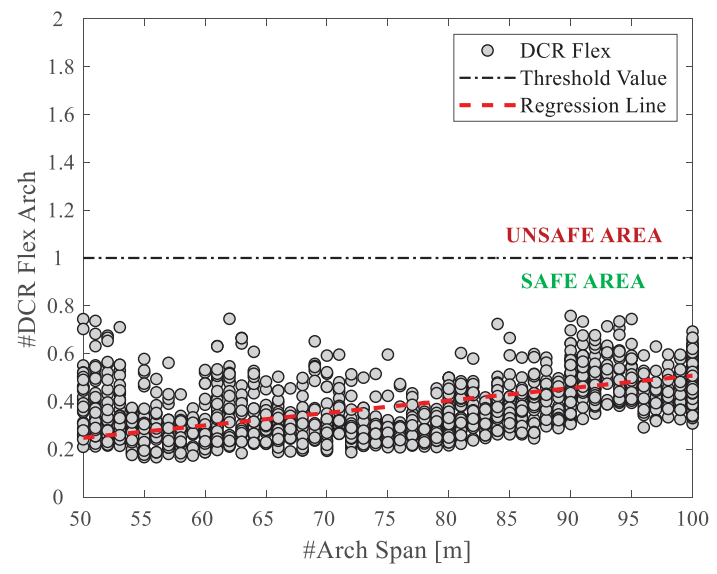

(a)

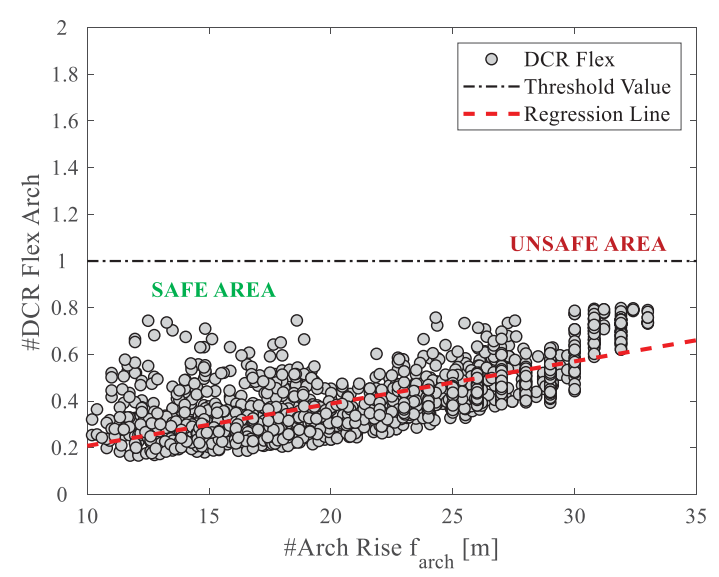

(c)

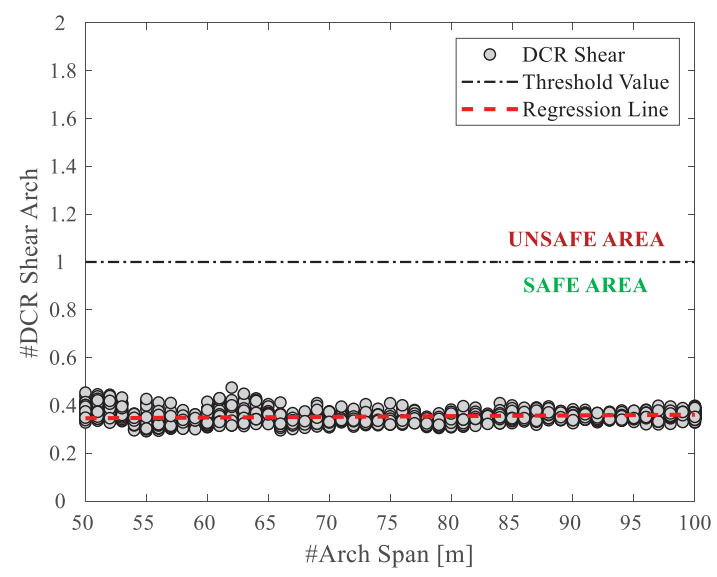

(b)

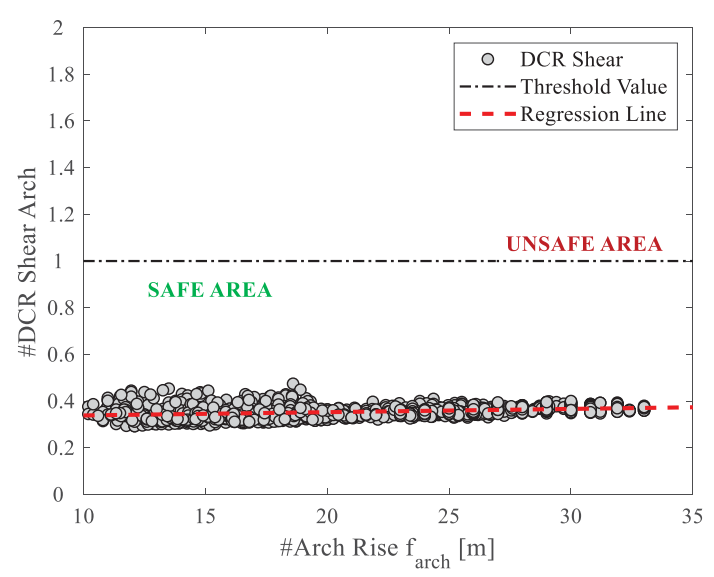

(d)

Figure 6: Demand over Capacity Ratio (DCR) distribution in the arch for flexural and shear failure, respectively, vs. : a)-b) Arch Span, L; c)-d) Arch Rise, farch.

Figure 7 shows the trend of the maximum DCR for the piers in function of arch span length and arch rise with reference to flexural (Figure 7a-c) and shear (Figure 7b-d) failures. It can be noted that the flexural problems are very prominent if compared to the shear ones, 
especially as the span and the rise of the arch increases. This is due to the fact that the piers, as previously mentioned, were verified in section 2.2 under axial forces only due to the assumption of simple hinges at their ends, according to a common practise of the time. This means that, under only axial forces, a fairly lower percentage of steel was required to satisfy the verifications if compared to the case of elements subjected to shear and bending moment.

However, in many real cases details were built at the ends in order to let the piers work as fixed elements and not as pendulums. As previously discussed, the presence of the pendulums drastically reduced, indeed, the hyperstatic unknowns and, thus, the complexity of the solution of the structural scheme of the bridge, but, at the same time, the relevant differences in the stiffness of the deck beam and the vault ensured that, under gravitational loads only, the neglected stresses were however limited even considering the hinges at the ends.

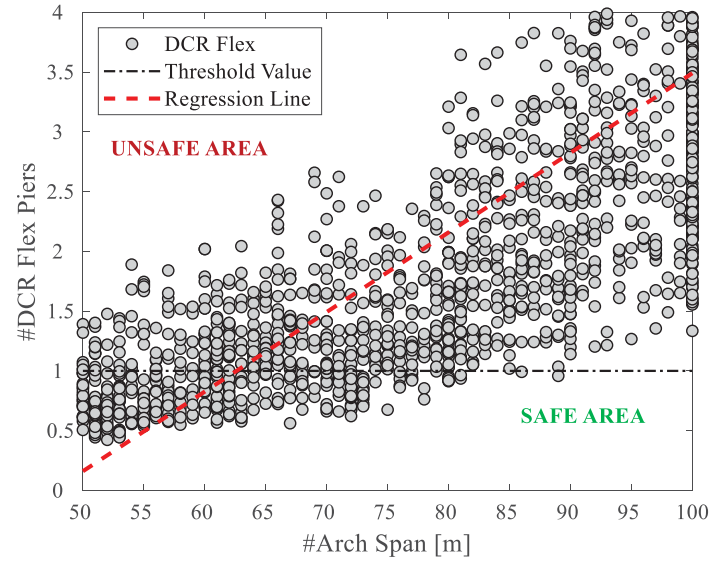

(a)

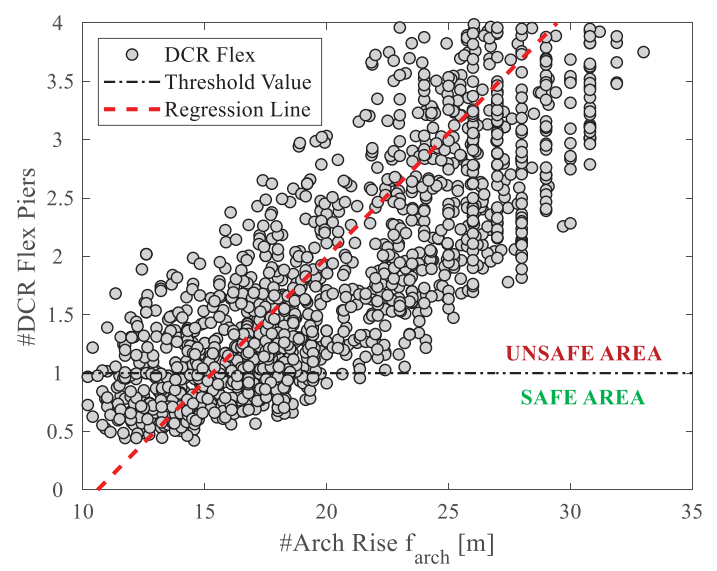

(c)

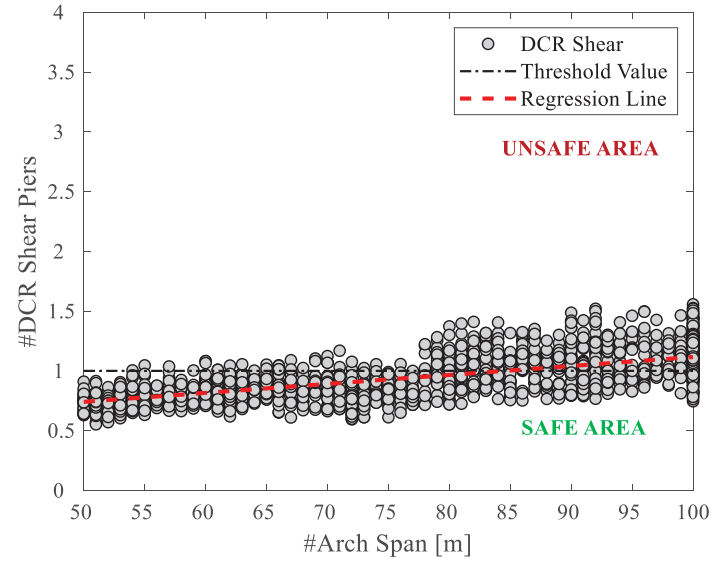

(b)

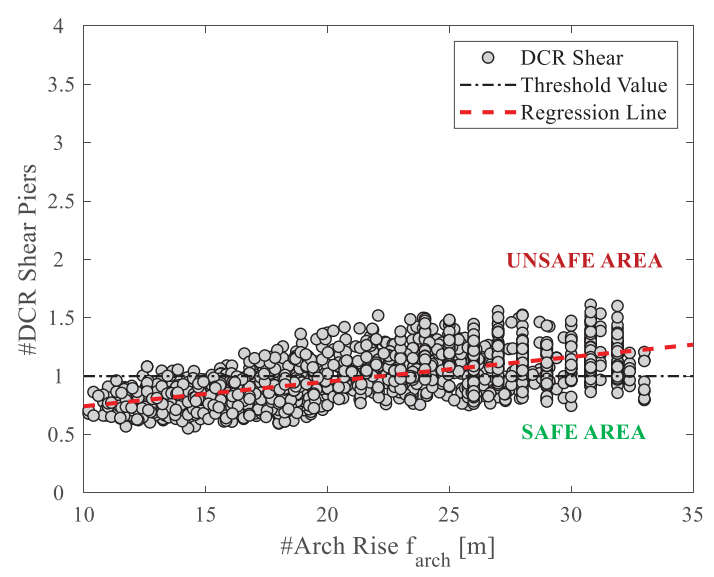

(d)

Figure 7: Demand over Capacity Ratio distribution in the piers for flexural and shear failure vs.: a)-b) Arch Span, L; c)-d) Arch Rise, $f_{\text {arch. }}$.

Clearly, in addition to the different constraining conditions introduced in the SAP model, the loads combinations adopted in the verifications herein presented, being more demanding than those considered at the design time both in terms of gravitational loads and of presence of horizontal actions, as the braking and acceleration forces, not considered in the past, have also contributed to have values of DCR in the piers higher than 1. This topic will become even more important for the verifications of the piers under seismic actions because they 
became mandatory only in the most modern regulatory codes and, thus, it is expected that higher stresses would be present in the piers for the acceleration loads provided by the current codes. Therefore, under the design seismic actions, the constraint conditions at the ends of the piers will make even more the difference. For the beams of the deck, for the sake of simplicity, the distributions of the maximum DCR have not been reported, because, as for the arch, there aren't criticisms related to bending or shear failures. It is worth to remember that the deck of these bridges, and therefore the beams, are characterized by a high flexural stiffness in comparison with the arch. Thus, if the moment of inertia of the deck and of the vault cross section are denoted as $I_{d}$ and $I_{a}$, for a "Maillart - Type" Arch Bridge, the ratio $I_{d} / I_{a}$ is very large: in particular, manuals and historical sources indicate that the minimum value of this parameter has to be about 50 ([4]) for such a bridge typology.

Finally, the analysis of the Demand-to-Capacity ratios highlighted that, under the current vertical loading conditions, for "Maillart - Type" Arch Bridge the piers are the most vulnerable structural elements. In particular, the maximum DCR ratio is attained for flexural failure in the outermost piers with respect to the crown of the arch, i.e., the slenderest ones. It is worth noting that, although the ratios $f_{\text {arch }} / L$ range in $0.2-0.3$, for spans of $80-100 \mathrm{~m}$, there are piers with a length of about $20 \mathrm{~m}$, which are characterized by a very important bending demand. These piers, on the contrary, are characterized by a flexural capacity not very adequate, because, as previously discussed, they were designed to bear only compression force.

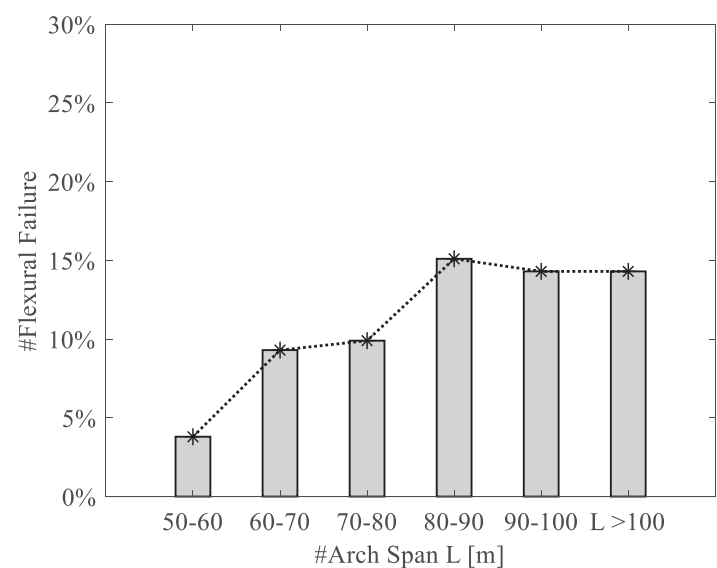

(a)

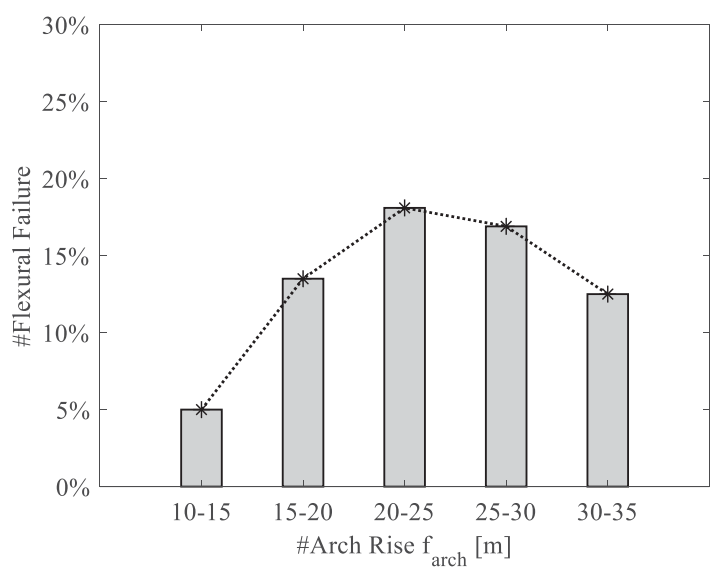

(c)

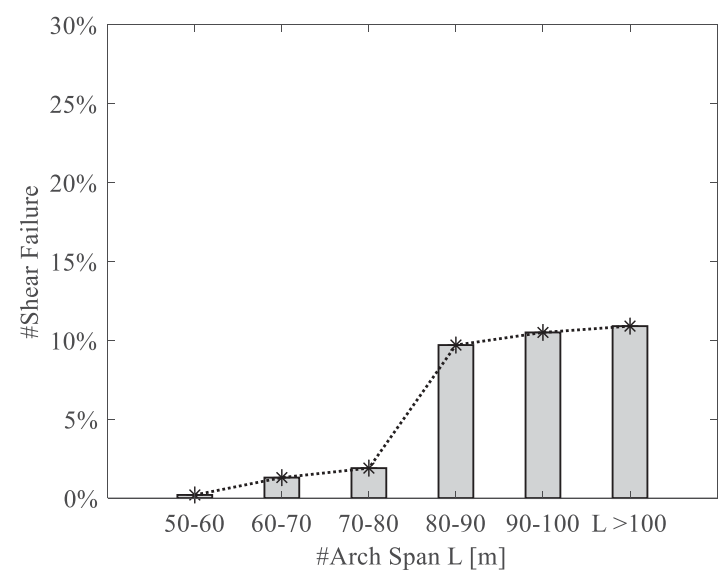

(b)

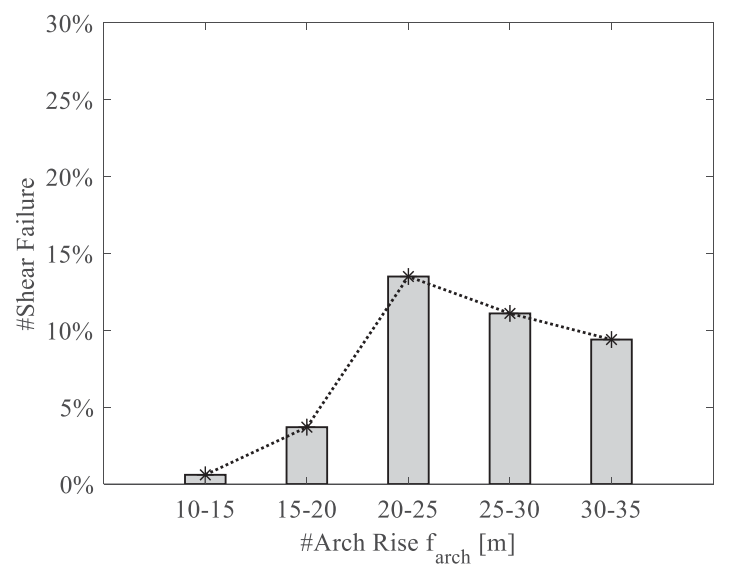

(d)

Figure 8: Distribution of failures for flexural and shear failure vs. a)-b) Arch Span L; c)-d) Arch Rise, farch. 
A global view of the obtained results for the examined numerical database of 1500 bridges can be represented by the percentages of failures, differentiated according to the type of failure and distributed in the variation ranges of span and arch rise in the inventory. Figures $8 \mathrm{a}$ and $8 \mathrm{~b}$ report, indeed, the failure percentage with reference to flexural and shear failures, respectively, versus the arch span, L. Analogously, Figures $8 \mathrm{c}$ and $8 \mathrm{~d}$ report the failure percentage versus the arch rise. It is worth noting that the number of analysed structures, for each subclass of the rise and span of arch within the selected ranges, is fairly uniform, as it is evidenced in the diagrams of Figures 9 and 10 that report the number of failed bridges (for flexure in Figure 9 and for shear in Figure 10) and the number of the generated ones for the fixed ranges of arch rise and arch span.

Representations shown in Figures 8, 9 and 10 are very useful to highlight how many structures, for each subclass, have showed at least one failure on the total number of bridges of the subclass. It is worth to remember, once again, that the sample of bridges was generated and verified through a simulated design, adopting, thus, reinforcement ratios indicated in the regulations of the time, defined and controlled also according to some original designs and drawings. Therefore, such results necessarily reflect the characteristics of the inventory of bridges defined in the previous section, and provide, for that inventory, an idea of damages that may affect such typology of bridges.

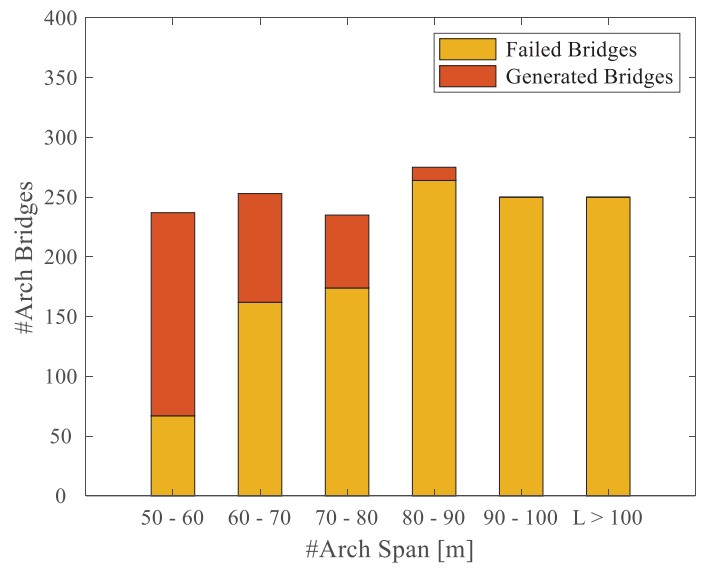

(a)

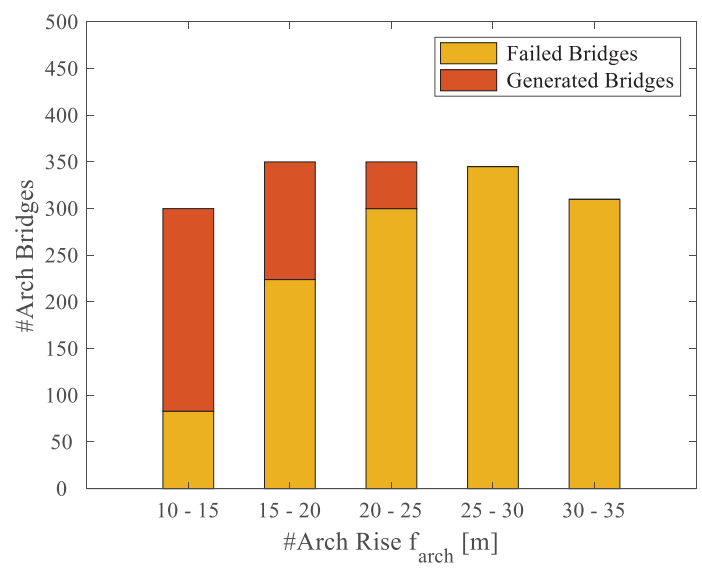

(b)

Figure 9: Distribution of failed bridges compared to generated bridges (flexural failure).

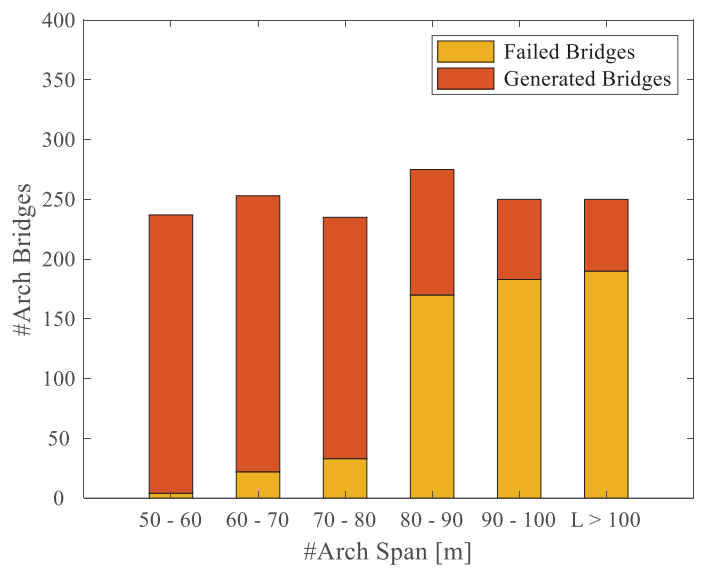

(a)

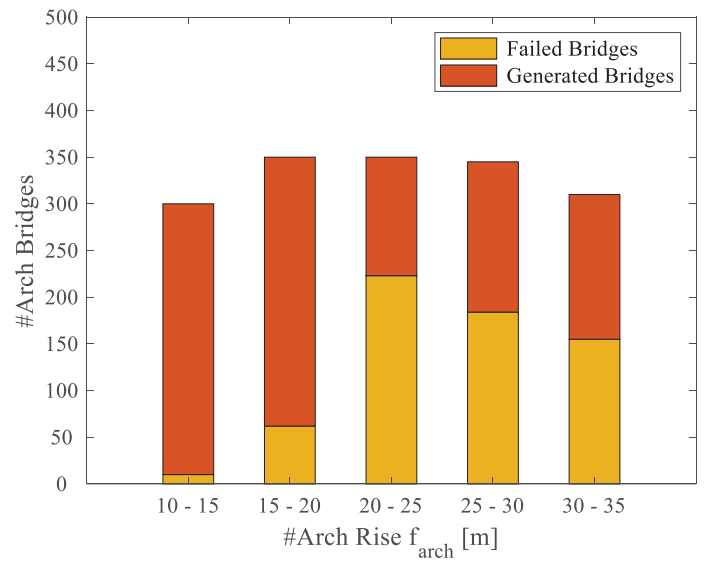

(b)

Figure 10: Distribution of failed bridges compared to generated bridges (shear failures). 
The study of the behaviour of these structures at large scale is, indeed, a crucial point for planning risk mitigation programs and for understanding how to prioritise the interventions for risk reduction. Moreover, since the failures are localized at the piers, above all at their ends for flexural problems and along the element for the short piers at the arch keystone, the structural reinforcement of these bridges through the use of FRP, i.e. Fiber Reinforced Polymers, could represent an efficient solution that would allow to realize non -invasive and reversible interventions for improving the structural performance ([22], [23]). Clearly, further studies are in progress aimed to assess the performance of the same inventory of bridges under the design seismic actions provided by the current codes and verify if the critical elements are the same identified in the analysis under the load combinations herein presented.

\section{CONCLUSIONS}

The paper presents the performance of Reinforced Concrete "Maillart-Type" Arch Bridges, also known as "RC Deck - Stiffened" Arch Bridges, under the gravitational and the moving loads prescribed by the current mandatory codes for bridges.

The structural performance has been evaluated by means of a linear analysis implemented in a Finite Element (FE) model for a Bridge Inventory made of more than 1500 structures, which have been generated by means of the Monte Carlo simulation method considering fixed variation ranges of several geometrical parameters. Each bridge within the inventory has been verified based on the typical design approaches adopted in the 50s and under the loading conditions required by the Codes of the time (i.e. only gravitational loads). Successively, according to current guidelines (Italian Building Code and New Guidelines for existing bridges), the performance of the designed bridges has been assessed considering the current non seismic design actions.

The analyses evidenced that at the Ultimate Limit State, flexural failures occur in the most external piers, which are also the slenderest ones, while shear failures occur mainly in the short piers at the arch keystone. This is due to the fact that the piers were designed only for axial forces and schematized as pendulums even if, in many cases, they were built as fixed elements at both ends and with some additional steel reinforcements. Therefore, the design assumption of pendulum scheme led to a fairly lower percentage of steel if compared to elements subjected to shear and bending moment. Conversely, no flexural or shear failures occur in the arch and in the beams of the deck.

This study allowed to identify the main vulnerabilities of this type of bridge under the current gravitational and moving loads and to highlight the opportunity for future developments, which could include the definition of different structural strengthening systems in order to improve the structural capabilities of such bridges. Further studies will investigate the same bridge inventory, herein defined, under the seismic actions provided by the current Italian codes to better understand the global vulnerability of such bridges under both static and seismic loading conditions.

\section{ACKNOWLEDGEMENTS}

This paper was developed under the financial support of "ReLUIS DPC 2019/2021WP4/Task 5.4 - Interventi di rapida esecuzione a basso impatto ed integrati per ponti esis- 
tenti", funded by the Italian Department of Civil Protection (DPC). This financial support is gratefully acknowledged.

\section{REFERENCES}

[1] Gentile R, Nettis A, Raffaele D. Effectiveness of the Displacement-Based seismic performance Assessment for continuous RC bridges and proposed extensions. Eng Struct 2020;221:110910. https://doi.org/10.1016/j.engstruct.2020.110910.

[2] Modena, C., Tecchio, G., Pellegrino, C., da Porto, F., Donà, M., Zampieri, P., \& Zanini, M. A. (2015). Reinforced concrete and masonry arch bridges in seismic areas: typical deficiencies and retrofitting strategies. Structure and Infrastructure Engineering, 11(4), 415-442.

[3] Billington, D. P. (1973). Deck-Stiffened Arch Bridges of Robert Maillart. Journal of the Structural Division. 99(7):1527 - 1539.

[4] Franciosi, V. Scienza delle Costruzioni, Volume 3, Tomo 2. 1971. (Liguori Editore) (in Italian).

[5] Billington, D. (2000). "The revolutionary bridges of Robert Maillart". Scientific American, 283(1), 84-91.

[6] Crisci G., Ceroni F., Lignola G.P., Prota A. (2020). Structural peculiarities of Maillart Type Arch Bridges. In Proceedings of Italian Concrete Days 2020.

[7] Crisci G., Ceroni F., Lignola G.P., Prota A. (2020). Seismic Response of RC Deck Stiffened Arch Existing Bridges. In Proceedings of the 18th International Conference of Numerical Analysis and Applied Mathematics, Rhodes, Greece, 17-23 September 2020.

[8] Bossio, A., Fabbrocino, F., Monetta, T., Lignola, G.P., Prota, A., Manfredi, G., Bellucci, F. Corrosion effects on seismic capacity of reinforced concrete structures (2019) Corrosion Reviews, 37 (1), pp. 45-56. DOI: 10.1515/corrrev-2018-0044.

[9] De Matteis G., Bencivenga P., Zizi M., Del Prete A.; 2019: Rischio strutturale di ponti esistenti: considerazioni preliminari sullo scenario in provincia di Caserta. In Proc. XVIII Convegno ANIDIS, Ascoli Piceno, Italy.

[10] Italian Building Code Aggiornamento sulle Norme Tecniche per le Costruzioni, D.M; Italian Ministry of Infrastructures and Transportation: Rome, Italy, 2018.

[11] Linee guida per la classificazione e gestione del rischio, la valutazione della sicurezza ed il monitoraggio dei ponti esistenti, Italian Ministry of Infrastructures and Transportation: Rome, Italy, 2020.

[12] Crisci G., Ceroni F., Lignola G. P., Prota A. Vulnerability of Existing RC Deck Stiffened Arch Bridges under Seismic Actions.

[13] Gentle, J. E. (2006). Random number generation and Monte Carlo methods. Springer Science \& Business Media.

[14] Royal Decree $\mathrm{n}^{\circ}$ 2229, "Norme per la esecuzione delle opere in conglomerato cementizio semplice ed armato", November 11th 1939. (in Italian). 
[15] Ministry of Public Works: ircular $n^{\circ}$ 6018, "Carichi da considerare nel calcolo dei ponti”, June 9th 1945, (in Italian).

[16] Weiwei L and Teruhiko Y Bridge Engineering Classifications Design Loading and Analysis Methods (Butterworth Heinemann).

[17] Computer \& Structures Inc. (CSI) SAP2000 Integrated Software for Structural Analysis and Design Computers and Structures Inc. Berkeley California.

[18] European Committee for Standardization. Eurocode 2: Design of concrete structures Part 1: General rules and rules for buildings. BS EN 1998-1: 2004.

[19] Álvarez, J. J., Aparicio, A. C., Jara, J. M., \& Jara, M. (2012). Seismic assessment of a longspan arch bridge considering the variation in axial forces induced by earthquakes. Engineering Structures, 34, 69-80.

[20] Matlab. (2018). Version 9.4.0.813654 (R2018a). Natick, Massachusetts: The MathWorks Inc.

[21] Biskinis, DE, Roupakias GK and Fardis MN., 2004, Degradation of shear strength of reinforced concrete members with inelastic cyclic displacement, ACI Structural Journal, 101(6), 773-783.

[22] Zinno, A., Lignola, G.P., Prota, A., Manfredi, G., Cosenza, E. "Influence of free edge stress concentration on ef-fectiveness of FRP confinement "(2010) Composites Part B: Engineering, 41 (7), pp. 523-532. DOI: 10.1016/j.compositesb.2010.07.003

[23] Lignola, G.P., Nardone, F., Prota, A., Manfredi, G. "Analytical model for the effective strain in FRP-wrapped circular RC columns" (2012) Composites Part B: Engineering, 43 (8), pp. 3208-3218. DOI: 10.1016/j.compositesb.2012.04.007 